\title{
STREAMFLOW CHARACTERISTICS OF NORTHEASTERN TASMANIA: I. REGIONAL FLOOD FLOWS
}

\author{
by A. D. Knighton
}

(with four tables and seven text-figures)

\begin{abstract}
KNIGHTON, A.D., 1987 (30:vi): Streamflow characteristics of northeastern Tasmania: I. Regional flood flows. Pap. Proc. R. Soc. Tasm., 121: 23-33. https://doi.org/10.26749/rstpp.121.23 ISSN 0080-4703. Department of Geography, University of Sheffield, Sheffield, United Kingdom SI0 2TN.

Based on streamflow records from thirteen stations, regional equations are developed which enable the estimation of mean annual discharge and various flood flows at ungauged sitesalong rivers in northeastern Tasmania. The area around Swansea is shown to be hydrologically distinct, at least as far as flood discharges are concerned, and the analysis subsequently focuses on the rest of the region. Despite the wide range of climatic and physiographic conditions there, relationships are highly significant, with drainage area explaining more than $97 \%$ of the variation in flood discharge. Rates of change are not only relatively high but increase with flood magnitude, suggesting rapid downstream transmission of flood waters. Network magnitude may be a viable alternative to drainage area as an estimator. Its use has the advantage that the downstream pattern of flow addition can be readily charted for major rivers, as illustrated for the Ringarooma and George.
\end{abstract}

Key Words: Tasmania, stream flow, drainage area, flood discharge.

\section{INTRODUCTION}

The basic variable used to express the size and erosive effectiveness of natural rivers is discharge, which is generally measured at established gauging stations. However, the number of measurement sites within an area is usually quite small and rarely does a sequence of gauging stations exist along an individual river. Consequently, in order to extend a spatially limited data base and provide estimates of flow characteristics at ungauged sites, some form of regional analysis is necessary. The estimates so derived can be used for water management and river engineering purposes at regional and basin scales, as well as for routing water and sediment through individual catchments. Indeed the latter provided the initial stimulus for this study in that reliable flow estimates were required as a spatial series along the Ringarooma and George Rivers in order to model the movement patterns of materialintroduced from mining sources. Although so inspired, the results presented below have implications for a wider range of purposes.

The study falls into two parts, the first of which is concerned with flood flow estimation and the second with hydraulic geometry relationships. Both deal with rivers in northeastern Tasmania, a somewhat arbitrarily defined area bounded in the west by a line along the Tamar estuary, South Esk and Macquarie Rivers (fig. 1). The southern limit is defined by the southern-most sweep of the
Macquarie River. Regional flow analyses are a compromise to a certain extent: between a larger sampled area with more gauging stations and a smaller one in which flow conditions are likely to be more homogeneous. Thus enlargement of the sampled area to augment the data base increases the degree of heterogeneity and the attendant risk of sampling from different hydrogeogra phic populations. Such proved to be the case here.

The area can be divided into three main sections. That to the north of the South Esk basin has rivers draining to the east and north coasts and to the Tamar estuary, so that they come under a wide range of climatic and physiographic influences. Mean annual precipitation is at a maximum $(>1600$ $\mathrm{mm})$ to the north and northeast of Ben Nevis, where many rivers (notably the North Esk, Ringarooma, George and South Esk) have their headwaters. The first three rivers listed provide a west-east sample across this northern section, the pattern of their mean monthly discharges being distinctivelyseasonal(fig. 2) and typically temperate oceanic (Shaw 1983). Despite the broadly similar regimes with July-September and January-March being respectively the maximum and minimum flow periods, small but possibly significant differences are apparent in the monthly runoff patterns, particularly between the George and the other two rivers. Even when dealing with averaged 


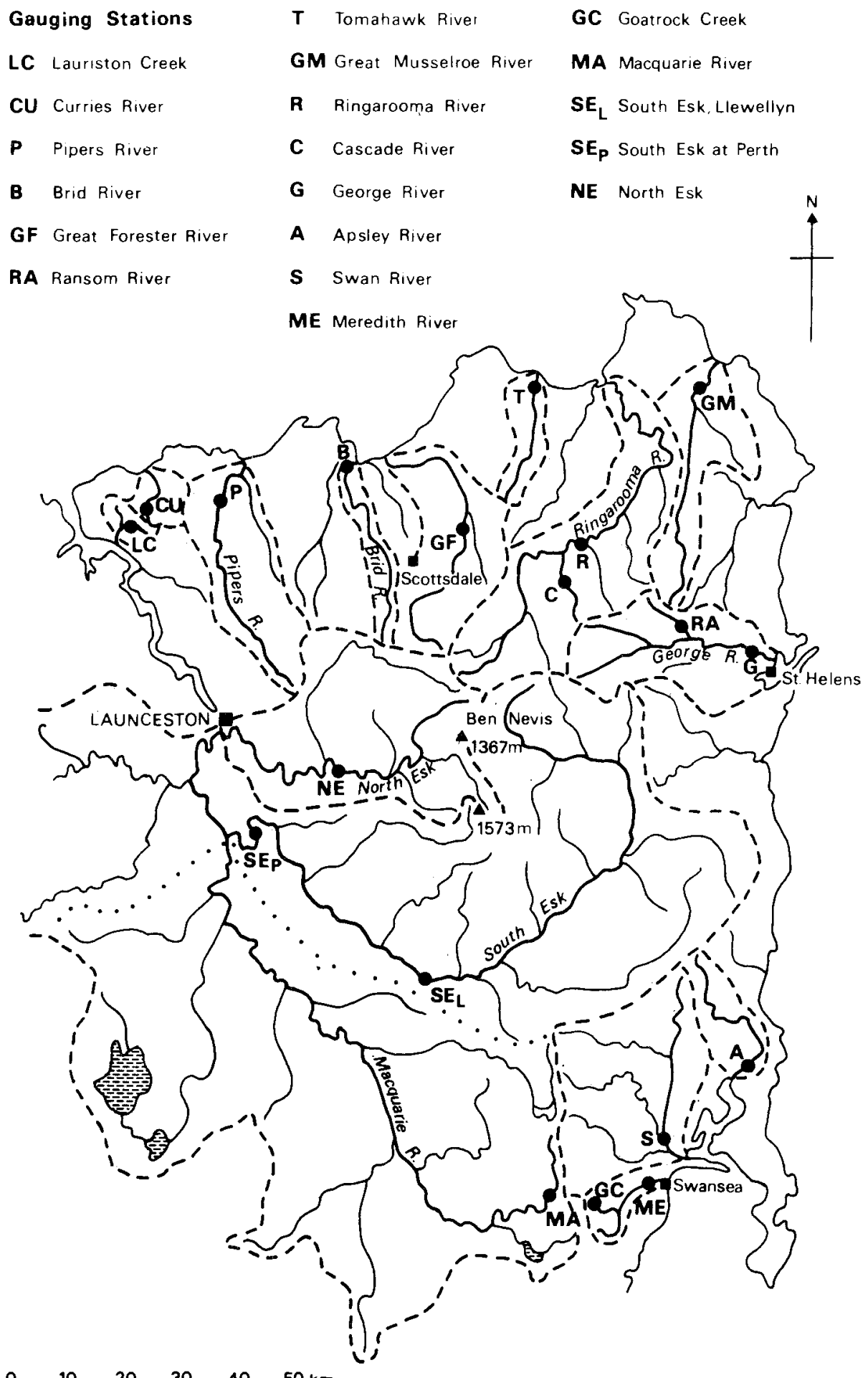

FIG. 1 - Distribution of gauging stations in northeastern Tasmania. 
flows in neighbouring basins, flow behaviour can be variable.

The South Esk basin dominates the area with the main river describing a horseshoe-like course (fig. 1) along which mean annual precipitation varies from $1600 \mathrm{~mm}$ in the upper reaches to less than $600 \mathrm{~mm}$ south of Perth. The main tributary, the Macquarie River, has a southern origin and enters the South Esk downstream of Perth, the site of the gauging station with the largest drainage area used in this study. In effect the South Esk basin separates the northern section from a southern one represented by a cluster of gauges in the neighbourhood of Swansea (fig. 1). There, mean annual precipitation ranges from 650 to $900 \mathrm{~mm}$. As the following analysis will show, this southern section has streamflow properties which are distinct from those further north.

\section{REGIONAL ANALYSIS}

The estimation of flood frequency or hydrograph parameters at ungauged sites commonly relies on statistical relationships between river flow and catchment characteristics. The latter can be broadly grouped into climatic, surface cover (soils and land use) and drainage basin properties, categories which include a potentially large number of operational variables. Ease and reliability of measurement, and likely success in prediction are appropriate criteria in the choice of suitable variables. From the point of view of the first criterion, drainage basin properties are probably the most suitable provided reliable topographic maps are available at a large enough scale. Those properties can be further subdivided into:

(i) size variables - drainage area, mainstream length, total channel length;

(ii) slope properties of the channel and hillslope systems; and

(iii) channel network variables drainage density, stream frequency, network magnitude;

with drainage area and network magnitude being relatively easy to measure. As regards the second criterion, drainage area has consistently been an effective variable, one reason for its success being that it subsumes a great deal of relevant hydrological information. In probably the most comprehensive study of streamflow variation yet completed (NERC, 1975), drainage area proved to be the single most important variable influencing the mean annual flood $\left(Q_{2.33}\right)$ at both national and regional levels of the British Isles. In assessing ten regional flood-frequency analyses from the United States, Riggs (1973) found that drainage area was
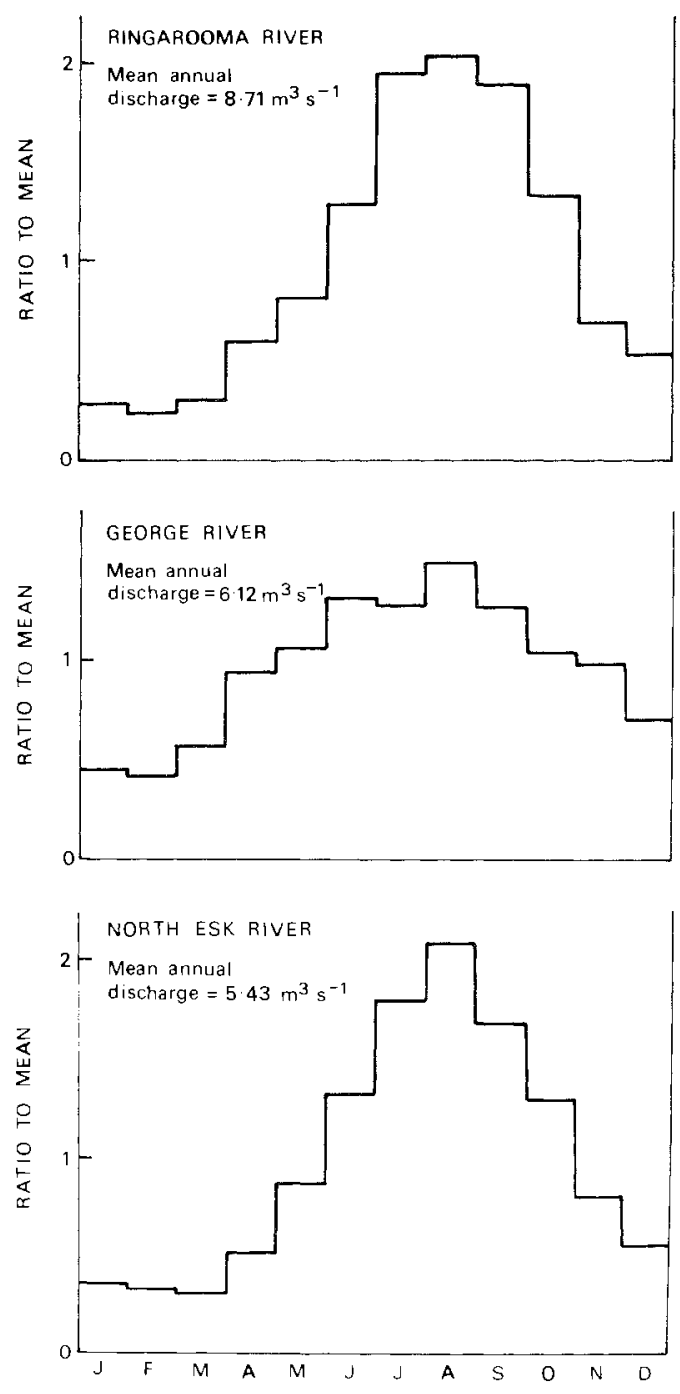

FIG. 2 - Flow regimes of the Ringarooma, George and North Esk Rivers expressed by the ratio of mean monthly to mean annual discharge.

the most consistent out of 16 independent variables since it was the only one to appear in all ten analyses. Given also that drainage area has been successfully used to predict the median flood $\left(\mathrm{Q}_{2}\right)$ in western Tasmania (Watson 1975, Watson \& Williams 1983), its choice for this study seems obvious, especially since this study is largely of an exploratory nature. Following standard practice, least-squares regression analysis is used to derive the required relationships which are assumed to have the typical log-linear form. 


\section{Mean Annual Discharge}

Mean annual discharge is simply the arithmetic average of all daily mean flows, with a frequency of $29,32.5$ and $30 \%$ respectively at the North Esk, Ringarooma and George gauging stations. In most humid areas it is closely related to drainage area and mean annual precipitation. Here, its relationship to drainage area is highly significant with a coefficient of determination $\left(\rho^{2}\right)$ of 0.98 and a standard error of estimate of 0.11 (fig. 3). Basins of less than $30 \mathrm{~km}^{2}$ rarely figure in such plots but there are three in this area and they plot well relative to other points.

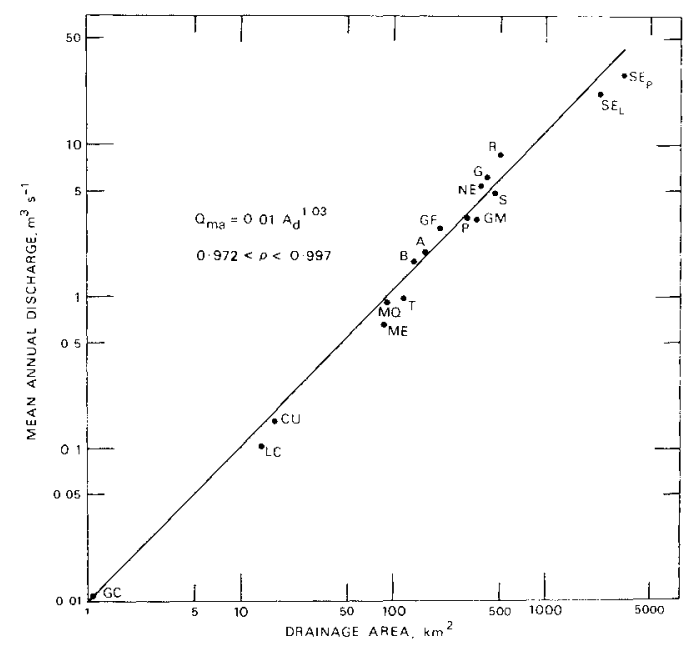

FIG. 3 - Relationships of mean annual discharge to drainage area. The $95 \%$ confidence limits for the correlation coefficient are given.

Over much of the eastern United States where total precipitation varies gradually with distance and each unit area contributes about the same volume of runoff, mean annual discharge tends to have a one-to-one relationship with drainage area (Dunne \& Leopold 1978). Such is the case here despite the less uniform pattern of rainfall. Indeed quite steep precipitation gradients exist from the coastal and South Esk valley areas toward the northern highlands. In addition to an exponent value of almost one, the regression equation (fig. 3) has an intercept value which indicates that on average a mean annual discharge of $0.01 \mathrm{~m}^{3} \mathrm{~s}^{-1}$ is produced from a unit basin area.

Such is the dominance of drainage area that no improvement in the level of explanation was achieved by the inclusion of mean annual precipitation as an additional independent variable. Nevertheless, most of the residuals above the regression line have higher than average precipitation, while those below have lower than average. That the two South Esk stations plot as negative residuals can be partly attributed to the precipitation effect, although channel storage may be a contributory factor at these large drainage areas. However, exciusion of those stations to give

$$
\mathrm{Q}_{\mathrm{ma}}=0.01 \mathrm{~A}_{\mathrm{d}}^{1.02}
$$

has obviously little effect on a well-defined regional trend which is maintained over three and a half cycles of logarithms.

\section{Flood Discharges and Drainage Area}

The main part of this paper is concerned with higher magnitude flows which are more relevant hydrologically and morphologically. Flood frequency analysis is a procedure for estimating the peak discharge which on average is likely to be equalled or exceeded once in a specified period of $T$ years. Thus $Q_{T}$ is the peak flow having a return period or recurrence interval of $T$ years. Before proceeding to the regional stage, the magnitudes of specified flood flows had to be determined for each of the gauging stations.

One basis for flood frequency analysis is the annual maximum series which takes the single peak discharge in each year of record so that the number of data values equals the record length in completed years. Ten years is generally regarded as the minimum period for analysis and, with one exception, this prescription was followed (table 1). Lauriston Creek was specifically included to extend the data base into the lower end of the drainage area range where there are few data but, despite only seven years of record, the additional error involved is probably quite small, particularly in the estimation of average floods. Having ranked the annual peak flows and calculated their recurrence intervals from $(n+1) / r$ (where $n$ is the number of years of record, $r$ is the rank of a particular flood), a suitable frequency distribution has to be chosen. There is no unequivocal theoretical basis for choosing the correct distribution to describe an annual maximum series but the log-Pearson Type III is widely accepted (Benson 1968, NER C 1975) and, in common with Watson (1975), it was used here because of its objectivity. Generally it provided a good fit to the data, although several of the plots had a hint of sinusoidal autocorrelation within the residuals. The graph for the North Esk (fig. 4) 


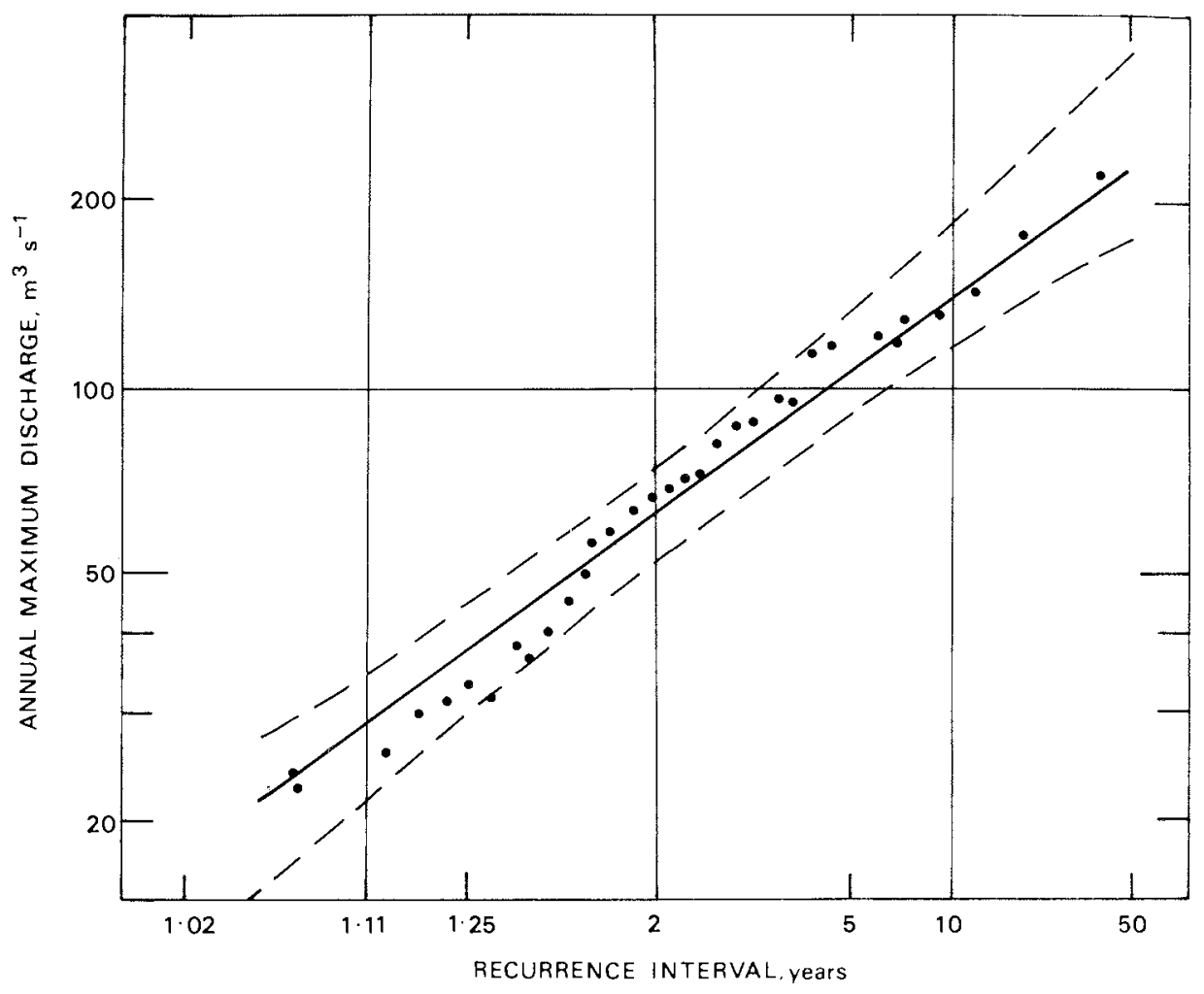

FIG. 4 - Flood-frequency plot for the North Esk at Ballroom, 1950-1983. The 95\% confidence limits are shown.

\section{TABLE 1}

\section{Flood flow data.}

\begin{tabular}{|c|c|c|c|c|c|c|}
\hline \multicolumn{2}{|c|}{ Gauging station } & \multirow{2}{*}{$\begin{array}{l}\text { Length of } \\
\text { record } \\
\text { years }\end{array}$} & \multicolumn{4}{|c|}{ Flood discharges, $\mathrm{m}^{3} \mathrm{~s}^{-1}$ record, } \\
\hline $\begin{array}{l}\text { Index } \\
\text { number }\end{array}$ & River & & $\mathbf{Q}_{1.11}$ & $\mathbf{Q}_{2}$ & $\mathbf{Q}_{s}$ & $\mathbf{Q}_{10}$ \\
\hline 302200 & Swan & 20 & 97 & 490 & 892 & 1123 \\
\hline 302204 & Apsley & 15 & 82 & 188 & 325 & 433 \\
\hline 302205 & George & 11 & 46 & 116 & 213 & 292 \\
\hline 302208 & Meredith & 16 & 28 & 97 & 163 & 199 \\
\hline 302210 & Great Musselroe & 13 & 30 & 70 & 123 & 165 \\
\hline 302213 & Goatrock Creek & 10 & 0.9 & 1.8 & 2.9 & 3.6 \\
\hline 318017 & South Esk at Llewellyn & 25 & 204 & 523 & 971 & 1341 \\
\hline 318204 & North Esk & 34 & 29 & 64 & 108 & 142 \\
\hline 318208 & South Esk at Perth & 27 & 174 & 491 & 972 & 1390 \\
\hline 318215 & Lauriston Creek & 7 & 2.3 & 4.1 & 6.2 & 7.6 \\
\hline 319200 & Brid & 14 & 11 & 25 & 42 & 56 \\
\hline 319202 & Tomahawk & 13 & 15 & 24 & 33 & 40 \\
\hline 319204 & Pipers & 11 & 23 & 62 & 118 & 165 \\
\hline
\end{tabular}

The index number is the one used by the Rivers and Water Supply Commission of Tasmania. 

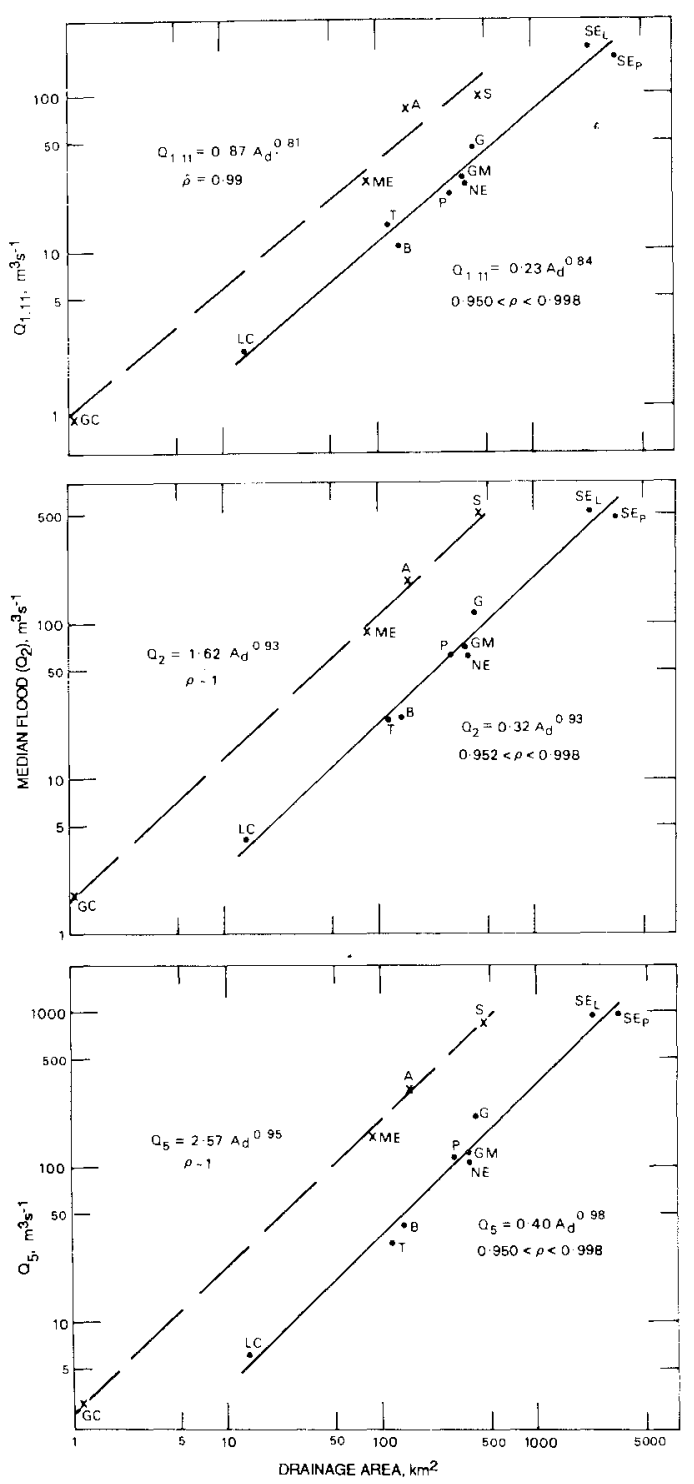

FIG. 5 - Relationships of flood flows, $Q_{1.11}, Q_{2}$ and $Q_{5}$, to drainage area for a southern and a northern/central section of northeastern Tasmania. The $95 \%$ confidence limits for the correlation coefficient are given.

illustrates these points, as well as showing how the 95\% confidence limits begin to widen away from a recurrence interval of two years which defines the median annual flood $\left(\mathrm{Q}_{2}\right)$. The mean annual flood has a recurrence interval of 2.33 years and the ratio of $\mathrm{Q}_{2.33} / \mathrm{Q}_{2}$ at the 13 gauging stations is fairly stable with a mean of 1.12 and a standard deviation of 0.02 . These average flows are important since it is believed that discharges in the neighbourhood of bankfull cumulatively perform most work in natural rivers and therefore are largely responsible for forming the channel (Knighton 1984).

A preliminary analysis in terms of the ratio $\mathrm{Q}_{2} / \mathrm{Q}_{\text {ma }}$ suggested that the 13 stations cover two rather than one hydrogeographic province, with the southern stations on the Swan, Apsley, Meredith and Goatrock Creek forming a separate group. The mean ratio there was 126 compared with 21 for the remaining stations. The subsequent plots confirmed the distinction (fig. 5), and the two areas were henceforth treated separately. Thus, while the initially selected region can be described by a single equation as regards mean annual discharge, the same homogeneity does not apply to flood flows. Indeed, comparing intercept values, flood flows in the southern section are about five times 1 - $^{-3 e r}$ than elsewhere.

All relationships are highly significant (table 2), even for the southern section where the data set is small. In fact, apart from $Q_{1.11}$, the four stations fit almost exactly along straight lines on $\log -\log$ graph paper (fig. 5) and standard errors are very low. The results for $Q_{10}$ are included largely for completeness since the records are not consistently long enough for good estimation of that flow, although the relationships retain the same level of significance. Thus table 2 provides two sets of equations which can be used for estimating a range of flood flows in the rivers of northeastern Tasmania. By way of example, the gauging station on the Ringarooma has seven years of record, the analysis of which gives a median flood value of 100 $\mathrm{m}^{3} \mathrm{~s}^{-1}$. The corresponding regional equation estimates the flow at $105 \mathrm{~m}^{3} \mathrm{~s}^{-1}$.

The form of the discharge-drainage area equation changes systematically with increasing recurrence interval, both the intercept value (a) and regression coefficient (b) becoming larger (table 2 ). This is the case in both sets of equations. The increase in intercept value is to be expected given that the sequence of relationships refers to progressively larger flood discharges and the intercept indicates the flow at a unit area, but it is interesting to note that the rate of increase between successive flows becomes less. However, more unusual is the progressive increase in regression coefficient. Ordinarily it decreases (table 3 ) because greater channel and valley storage attenuate the flood wave at higher flows. That the reverse is found here 
TABLE 2

Flood flow-drainage area relations, northeastern Tasmania.

$\begin{array}{lcccc}\begin{array}{l}\text { Flood } \\ \text { discharge }\end{array} & \begin{array}{c}\text { Equation } \\ \text { constants }\end{array} & \text { correlation } & \begin{array}{c}\text { Standard error } \\ \text { of estimate }\end{array}\end{array}$

(i) Northern area - nine stations

$\begin{array}{lllll}\mathrm{Q}_{1.11} & 0.23 & 0.84 & 0.99 & 0.10 \\ \mathrm{Q}_{2} & 0.32 & 0.93 & 0.99 & 0.09 \\ \mathrm{Q}_{5} & 0.40 & 0.98 & 0.99 & 0.10 \\ \mathrm{Q}_{10} & 0.45 & 1.01 & 0.99 & 0.11\end{array}$

(ii) Southern area - four stations

\begin{tabular}{lllll}
$\mathrm{Q}_{1.11}$ & 0.87 & 0.81 & 0.99 & 0.16 \\
$\mathrm{Q}_{2}$ & 1.62 & 0.93 & 0.99 & 0.03 \\
$\mathrm{Q}_{5}$ & 2.57 & 0.95 & 0.99 & 0.03 \\
$\mathrm{Q}_{10}$ & 3.24 & 0.95 & 0.99 & 0.03 \\
\hline
\end{tabular}

Symbols: $Q=a A_{d}^{b}$.

TABLE 3

Flood flow-drainage area relations.

\begin{tabular}{llllll} 
Source & Location & $\begin{array}{c}\text { Drainage } \\
\text { area, } \mathbf{k m}^{2}\end{array}$ & Discharge & a & b \\
\hline Benson (1962) & New England, USA & $4-25070$ & $\mathrm{Q}_{2.33}$ & 0.56 & 0.85 \\
& 164 stations & & $\mathrm{Q}_{5}$ & 0.97 & 0.82 \\
& & & $\mathrm{Q}_{10}$ & 1.51 & 0.79 \\
Thomas \& Benson & Potomac River basin, USA & $15-30000$ & $\mathrm{Q}_{2}$ & 0.86 & 0.80 \\
(1970) & & & $\mathrm{Q}_{5}$ & 1.74 & 0.78 \\
& & & $\mathrm{Q}_{10}$ & 2.80 & 0.76 \\
NERC (1975) & British Isles & $0.05-9868$ & $\mathrm{Q}_{2.33}$ & 0.68 & 0.77 \\
& 533 stations & & & \\
Watson (1975) & Western Tasmania & $449-2539$ & $\mathrm{Q}_{2}$ & 4.70 & 0.74 \\
& 7 stations & & & & \\
Watson \& & Western Tasmania & $15-2539$ & $\mathrm{Q}_{2}$ & 5.19 & 0.75 \\
Williams (1983) & 10 stations & & & \\
\hline
\end{tabular}

Symbols: $Q=a A_{d}{ }^{b}$.

may be due to the low levels of storage available so that translation rather than reservoir effects dominate the downstream transmission of flood waters. Comparing tables 2 and 3 , it appears that northeastern rivers do indeed increase their flood volumes downstream at a faster rate than do rivers in similar environments. On the other hand, the intercept values for the northern area are relatively small, particularly when compared with western
Tasmania which is wetter, steeper and more densely drained. Those for the southern area a re reasonably high, suggesting a greater capacity for flood flow generation within that group of streams.

The amount of scatter about the regression lines is small (fig. 5). In the northern area graphs the George and South Esk (Llewellyn) stations consistently appear as positive residuals, with the Brid, North Esk and South Esk (Perth) stations as 
negative residuals. This variation, although relatively small, points to inter-basin contrasts in flood generation and transmission. The two South Esk stations seem to be in the wrong order as regards flood volumes (table 1, fig. 5), possibly because water movement to the Perth station is more subject to the influence of temporary storage. However, exclusion of that station from the regressions had little effect on the form of the equations which, considering the range of environmental conditions covered, describe the data very well.

\section{Flood Discharges and Network Topology}

Intuitively it seems reasonable to argue that the way in which channels of different size are linked together within the drainage network can influence the movement pattern of flood waters and therefore the resultant flood volumes, especially at downstream locations. Certainly the Flood Studies Report (NERC 1975) includes stream frequency (number of channel segments per unit area) as an important explanatory variable of the mean annual flood and attempts have been made to relate parameters of the Instantaneous Unit Hydrograph to network variables (RodriguezIturbe \& Valdes 1979). There, however, the emphasis has been on Horton-Strahler rather than Shreve-Smart measures of drainage network composition. A major element in the more recent Shreve-Smart approach is the introduction of new topologic parameters which describe network structure in dimensionless terms. Two are considered here - magnitude and diameter. The magnitude of a channel link, an unbroken section of channel between successive nodes (sources, junctions or outlet), is defined as the number of sources upstream, while diameter is the maximum link distance within the network. Both have geometric equivalents - namely, drainage area and mainstream length. Indeed magnitude $(M)$ and drainage area $\left(A_{d}\right)$ are related theoretically (Shreve 1967) by

$$
A_{d}=K^{2}(2 M-1)
$$

where $\mathrm{L}$ is the average link length and $\mathrm{K}$ is a coefficient, but magnitude is easier to measure provided suitable maps are available.

Map scale is known to affect channel delineation and therefore the calculation of network indices, so that it has become common practice to take the blue-line network shown on 1:25000 maps as the initial basis for measurement. Unfortunately three of the nine northern stations are not yet covered by the new 1:25000 series, which reduces

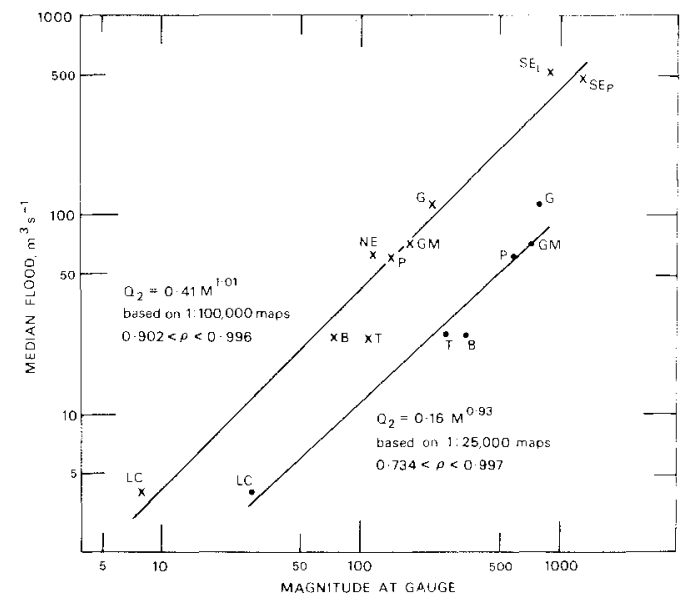

FIG. 6 - Relationship of the median annual flood to net work magnitude measured at two map scales, 1:25000 and 1:10000.

the data set to six and excludes the upper end of the scale represented by the South Esk stations. Based on measurements of link magnitude (M) and network diameter (D) at each of the six gauges, the following equations were obtained for the median annual flood $\left(Q_{2}\right)$

$$
\begin{aligned}
& \mathrm{Q}_{2}=0.16 \mathrm{M}^{0.93}(\rho=0.97, \mathrm{SEE}=0.13) \\
& \mathrm{Q}_{2}=0.33 \mathrm{D}^{1.09}(\rho=0.8 \mathrm{I}, \mathrm{SEE}=0.34)
\end{aligned}
$$

Although significant at the $95 \%$ level, the latter does not describe the distribution of data particularly well and is henceforth disregarded as a possible means of flow estimation.

The exponent in equation (3) is exactly the same as in the corresponding drainage area relationship (table 2, fig. 5), which supports the belief that the rate of downstream increase in $\mathrm{Q}_{2}$ along these northern rivers is faster than elsewhere. Again the Brid (northern coastal plain) appears as a negative residual and the George (sharply dissected and rugged headwaters) as a positive one, with the remaining points quite close to the line (fig. 6). For comparative purposes and to produce an equation applicable to those parts of the northern area outside that currently covered by the 1:25000 series, magnitude was determined from 1:100000 maps for the original nine northern stations and correlated with the median annual flood to give

$$
\mathrm{Q}_{2}=0.41 \mathrm{M}^{1.01}(\rho=0.98, \mathrm{SEE}=0.14)
$$

The regression coefficient is slightly larger than in equation (3) but the intercept value is significantly 
TABLE 4

Flood flow-network magnitude relations.

\begin{tabular}{lcccc}
$\begin{array}{l}\text { Flood } \\
\text { discharge }\end{array}$ & $\begin{array}{c}\text { Equation } \\
\text { a }\end{array}$ & $\begin{array}{c}\text { constants } \\
b\end{array}$ & $\begin{array}{c}\text { Correlation } \\
\text { coefficient }\end{array}$ & $\begin{array}{c}\text { Standard error } \\
\text { of estimate }\end{array}$ \\
\hline
\end{tabular}

(i) 1:25000 series - six stations

\begin{tabular}{lllll}
$\mathrm{Q}_{1.11}$ & 0.13 & 0.82 & 0.97 & 0.12 \\
$\mathrm{Q}_{2}$ & 0.16 & 0.93 & 0.97 & 0.13 \\
$\mathrm{Q}_{5}$ & 0.19 & 1.00 & 0.97 & 0.15 \\
(ii) 1:100 000 series - nine stations & & & & \\
$\mathrm{Q}_{1.11}$ & 0.28 & 0.92 & 0.98 & 0.12 \\
$\mathrm{Q}_{2}$ & 0.41 & 1.01 & 0.98 & 0.14 \\
$\mathrm{Q}_{5}$ & 0.54 & 1.06 & 0.97 & 0.17 \\
\hline
\end{tabular}

Symbols: $Q=a M^{\mathrm{b}}$.

so, indicating that a unit stream at 1:100 000 has on average a magnitude of about 3 at the larger scale. Although equation (5) explains the data quite well (fig. 6), it is not considered to be as reliable as equation (3) because that is based on 1:25000 maps which are both more recent and better defined as regards surface channels.

The fact that magnitude correlates reasonably well with $Q_{2}$ (and other flood flows, table 4) implies that it could be an effective alternative to drainage area as an estimator of flood discharge. In choosing between the two, likely success in prediction and ease of measurement have already been mentioned as appropriate criteria. Judging from the higher correlation and lower standard error of estimate, drainage area seems to be superior as a predictor but the magnitude relationship, which is based on fewer points, could be improved when the entire area is mapped at the 1:25000 scale. As regards the second criterion, the measurement of drainage area is usually straightforward but can be time consuming if flow is to be estimated at many ungauged sites. On the other hand, magnitude is easily measured and, because network structure can be simply stored in a computer as a binary string, the magnitude of any point can be readily determined. The main requirement is consistency in the delineation of networks and their constituent channels.

The use of magnitude has a further advantage. Since each channel link within a network has a particular magnitude, the discharge of each link can be estimated and the pattern of flow addition from tributary sources traced for major rivers. Based on measurements of network structure and the regional discharge-magnitude relationship (equation 3 ), the downstream pattern has been plotted for the George and Ringarooma rivers (fig. 7). Scale limitations do not allow the smaller tributaries to be shown but there is sufficient detail to indicate major differences between the two river systems. Whereas the George is characterised by infrequent, large-scale additions of flow, concentrated in the middle section, the Ringarooma has a more regular pattern with smaller but more frequent tributary contributions along the entire length of the river. In part these differences can be associated with the more elongate form of the Ringarooma basin (fig. 1). Such plots emphasize the discontinuous nature of flow addition, which has implications for the transport of sediment and the adjustment of channel form. They may also provide a basis for more efficient water management and for routing flood flows through drainage networks.

\section{CONCLUSION}

Given that hydrologic response is influenced by many factors which are usually highly correlated and spatially variable, regional analyses based on equations having only one independent variable inevitably contain errors. Consequently flow estimation must be tinged with caution, especially if the available data base is relatively small as is the case here. Also, application of the results to longer time periods may be invalid if, as in New South Wales (Pickup 1976), the rivers are subject to fluctuating regimes over $30-50$ year periods. Set against these reservations is the high level of significance achieved by the regional relationships for northeastern Tasmania, in which drainage area explains more than $97 \%$ of the variation in flood 


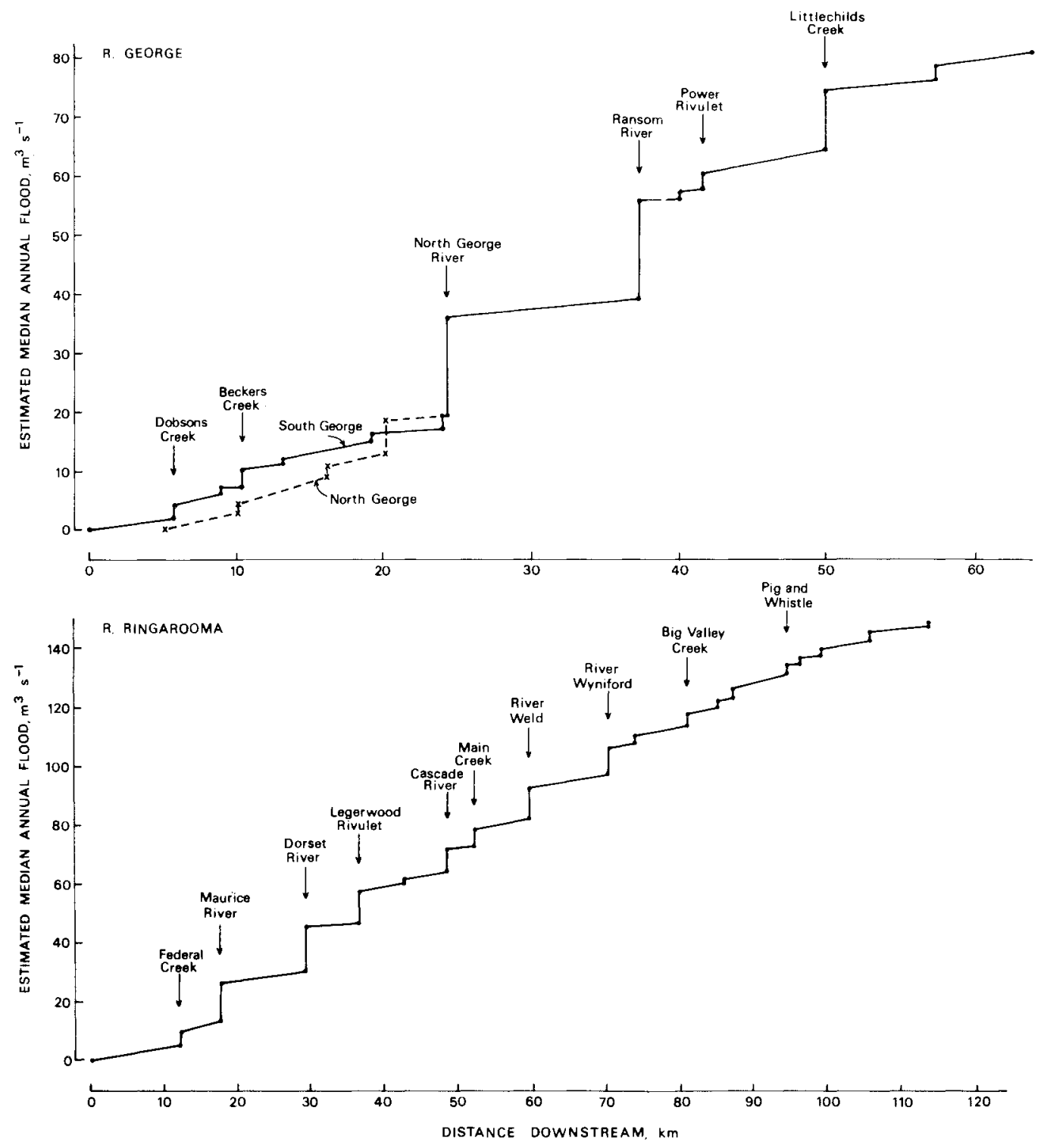

FIG. 7 - The downstream pattern of flow addition estimated from equation (3) for the George and Ringarooma Rivers.

discharges (table 2, fig. 5). Atypically the higher magnitude floods increase faster with drainage area than do the lower magnitude ones, which may reflect limited storage during the downstream transmission of flood water. The analysis has also shown that the rivers in the neighbourhood of Swansea are hydrologically distinct, with flood flows more than five times as large as those elsewhere in the area. Finer distinctions can be seen in the pattern of residuals from the northern regressions (figs 5 and 6 ). The George River, which drains one of the wettest catchments, and the South Esk at Llewellyn always appear as positive residuals, while the Brid and South Esk at Perth have the 
opposite quality. The Great Musselroe and particularly the Pipers Rivers show very little deviation from the regression lines and from that point of view may be regarded as typical basins worthy of more intensive study.

Network magnitude appears to offer a viable alternative to drainage area as an estimator of flood flows in single-variable equations. Its use provides an opportunity for charting the pattern of flow addition along major rivers (fig. 7) and may improve estimation procedures by taking account of tributary inflows. However, any further application must await the completion of the 1:25000 map coverage on which surface channels are better defined. Indeed the overall need is for more data to improve the reliability of results. The relationships obtained in this initial study should be re-evaluated in five years' time when the data base is more extensive through both an increased length of record and a larger number of suitable gauging stations.

\section{ACKNOWLEDGEMENTS}

I wish to thank The Royal Society and the University of Sheffield Research Fund for financial assistance; Dr Les Wood, the Head of the Department of Geography, University of Tasmania, for providing study facilities; Mike Williams of the Hydro-Electric Commission; and particularly Douglas Steane and Andrew Livingston of the Rivers and Water Supply Commission for making their flow records available.

\section{REFERENCES}

BENSON, M.A., 1962: Factors influencing the occurrence of floods in a humid region of diverse terrain. U.S.G.S. Water-Supply Pap. 1580-B: 64 pp.

BENSON, M.A., 1968: Uniform flood frequency estimating methods for federal agencies. Water Resources Research, 4: 891-908.

DUNNE, T. \& LEOPOLD, L.B., 1978: WATER IN EN VIRONMENTAL PLANNING. W.H. Freeman, San Francisco.

KNIGHTON, D., 1984: FLUVIAL FORMS AND PROCESSES. Edward Arnold, London.

NERC, 1975: FLOOD STUDIES REPORT. Natural Environment Research Council, London.

PICKUP, G., 1976: Geomorphic effects of changes in river runoff, Cumberland Basin, N.S.W. Aus tralian Geographer, 13: 188-193.

RIGGS, H.C., 1973: Regional analyses of streamflow characteristics. U.S.G.S. Techniques of WaterResources Investigations, Bk 4, Ch B3: 15 pp.

RODRIGUEZ-1TURBE, I. \& VALDES, J.B., 1979: The geomorphic structure of hydrologic response. Water Resources Research, 15: 1409-1420.

SHAW, E.M., 1983: HYDROLOGY IN PRACTICE. Van Nostrand Reinhold (UK), Wokingham.

SHREVE, R.L., 1967: Infinite topologically random channel networks. J. Geol., 75: 178-187.

THOMAS, D.M. \& BENSON, M.A., 1970: Generalization of streamflow characteristics from drainagebasin characteristics. U.S.G.S. Water-Supply Pap. 1975: 55 pp.

WATSON, B., 1975: Flood magnitude and frequency Part 1: West Coast of Tasmania, Annual Flood Series. Hydro-Electric Commission, Investigations Division Report: 9 pp.

WATSON, B. \& WILLIAMS, M.L., 1983: Flood peak estimation for small catchments on the west coast of Tasmania. Hydro-Electric Commission Investigations Division Report: $6 \mathrm{pp}$.

(accepted 15 September 1986) 